\title{
pH-responsive poly(aspartic acid) hydrogel-coated magnetite nanoparticles for biomedical applications
}

\author{
Jaime Vega-Chacón a,*, María Isabel Amaya Arbeláez b , Janaina Habib Jorge ${ }^{\text {b }}$, \\ Rodrigo Fernando C. Marques ${ }^{\text {, }}$, Miguel Jafelicci Jr ${ }^{\text {a }}$ \\ a São Paulo State University (UNESP), Institute of Chemistry, Araraquara, São Paulo, Brazil \\ b São Paulo State University (UNESP), School of Dentistry, Araraquara, São Paulo, Brazil
}

\section{A R T I C L E I N F O}

\section{Article history:}

Received 30 October 2016

Received in revised form 10 January 2017

Accepted 25 March 2017

Available online 29 March 2017

\section{Keywords:}

Magnetite nanoparticles

pH-responsive

Poly(aspartic acid)

Hydrogel

\begin{abstract}
A B S T R A C T
A novel multifunctional nanosystem formed by magnetite nanoparticles coated with pH-responsive poly(aspartic acid) hydrogel was developed. Magnetite nanoparticles $\left(\mathrm{Fe}_{3} \mathrm{O}_{4}\right)$ have been intensively investigated for biomedical applications due to their magnetic properties and dimensions similar to the biostructures. Poly(aspartic acid) is a water-soluble, biodegradable and biocompatible polymer, which features makes it a potential candidate for biomedical applications. The nanoparticles surface modification was carried out by crosslinking polysuccinimide on the magnetite nanoparticles surface and hydrolyzing the succinimide units in mild alkaline medium to obtain the magnetic poly(aspartic acid) hydrogel. The surface modification in each step was confirmed by DRIFTS, TEM and zeta potential measurements. The hydrodynamic diameter of the nanosystems decreases as the $\mathrm{pH}$ value decreases. The nanosystems showed high colloidal stability in water and no cytotoxicity was detected, which make these nanosystems suitable for biomedical applications.
\end{abstract}

(c) 2017 Elsevier B.V. All rights reserved.

\section{Introduction}

Stimuli-responsive polymers change their properties (solubility, shape, surface characteristics, etc.) in response to a variation of the environmental conditions such as temperature, $\mathrm{pH}$, electric or magnetic field, light, ultrasound, salt concentration, among others. Due to their unique properties, stimuli-responsive polymers offer many opportunities to introduce functionalities in nanostructures and enable the manufacture of various intelligent systems for application in biomedical field as imaging, disease detection, controlled drug delivery and bioseparation [1-3]. Among the so called stimuli-responsive polymers, pH-responsive polymers usually contain weakly acidic groups or weakly basic groups that will release protons or accept protons, respectively, in response to the $\mathrm{pH}$ variation, causing a macromolecular conformational change due to the repulsion of generated charges. This behavior has been harnessed as a mechanism for controlled drug release [4].

Poly(aspartic acid) (PASP) is a hydrophilic, biocompatible and biodegradable polymer that has received considerable attention in medicine, cosmetic and food industry [5]. PASP is commonly obtained through mild alkaline hydrolysis of polysuccinimide (PSI). This later is normally synthesized by L-aspartic acid thermal polycondensation. The repeat unit of PSI is a five-member imide ring (succinimide)

\footnotetext{
* Corresponding author.

E-mail address: jvegachacon@gmail.com (J. Vega-Chacón).
}

which is susceptible to nucleophilic attack, allowing its crosslinking using diamines to produce PSI gel. PASP hydrogel is obtained by mild alkaline hydrolysis of the PSI gel. Water absorption capacity of PASP bulk hydrogel has been showed to depend on $\mathrm{pH}$ and its variation can produce a shrinking or swelling of the hydrogel, conferring its hydrogel pH-sensitive behavior [6-9].

Nanosystems composed of magnetite nanoparticles coated with $\mathrm{pH}$ responsive polymers have been proposed for multiple applications in the biomedical field, among them contrast agent in magnetic resonance imaging (MRI), delivery systems (drugs, genes, proteins), magnetic hyperthermia, bioanalysis and immunoassays, cell labeling, enzyme immobilization, etc. [1,10-12]. These applications require colloidal stability of nanoparticles in water at the biological conditions. A current approach is based on coating magnetite nanoparticles with a hydrophilic biocompatible hydrogel [13-17].

Previous works of Aurich et al. [18] and Yang et al. [19] reported the preparation of non-toxic and colloidal stable PASP coated magnetite nanoparticles. Also, poly(aspartic acid)-poly(ethylene glycol) copolymers coated iron oxide nanoparticles were reported with suitable features for biomedical applications [20-22]. Particularly Kumagai et al. [23] showed the potential utility of these type of nanoparticles as tumor-selective MRI contrast agents. Yang et al. [24] described the õpreparation of iron oxide nanoparticles coated by octadecyl grafted poly(aspartic acid) loaded with doxorubicin. Their results suggested the simultaneously potential uses in cancer diagnosis by MRI and 
Table 1

Concentration of the reactants to produce $\mathrm{Fe}_{3} \mathrm{O}_{4}$-PSI.

\begin{tabular}{llll}
\hline Samples & $\mathrm{Fe}_{3} \mathrm{O}_{4}-\mathrm{NH}_{2}(\mathrm{mg} / \mathrm{mL})$ & $\mathrm{PSI}(\mathrm{mg} / \mathrm{mL})$ & $\mathrm{DAB}(\mu \mathrm{L} / \mathrm{mL})$ \\
\hline $\mathrm{Fe}_{3} \mathrm{O}_{4}-\mathrm{PSI}_{0}$ & 2.50 & 10 & 0 \\
$\mathrm{Fe}_{3} \mathrm{O}_{4}-\mathrm{PSI}_{1}$ & 2.50 & 10 & 1.0 \\
$\mathrm{Fe}_{3} \mathrm{O}_{4}-\mathrm{PSI}_{2}$ & 3.75 & 10 & 1.0 \\
$\mathrm{Fe}_{3} \mathrm{O}_{4}-\mathrm{PSI}_{3}$ & 2.50 & 10 & 1.3 \\
\hline
\end{tabular}

therapy. These works were focused on nanoparticles surface coating by PASP, it does not attempt to the $\mathrm{pH}$ responsive possibilities since PASP used was not crosslinked.

Although some authors have studied bulk pH-responsive behavior, to the best of our knowledge, there is no report on literature concerning the preparation of magnetite nanoparticle coated by PASP $\mathrm{pH}-$ responsive hydrogel. In this article, we report the development of novel multifunctional magnetic nanoparticle surface modified with poly(aspartic acid) hydrogel, with magnetic- and $\mathrm{pH}$-responsive features. In addition, the nanosystems show no cytotoxicity and the surface hydrogel confers it colloidal stability in water.

\section{Experimental section}

\subsection{Materials}

All chemicals were reagent grade and used without purification. Ferric chloride hexahydrate $\left(\mathrm{FeCl}_{3} \cdot 6 \mathrm{H}_{2} \mathrm{O}, 98 \%\right)$, ferrous chloride tetrahydrate $\left(\mathrm{FeCl}_{2} \cdot 4 \mathrm{H}_{2} \mathrm{O}, 99 \%\right), 3$-aminopropyl trimethoxysilane (APTS, 99\%), N,N-dimethylformamide (DMF, 99.8\%), L-aspartic acid (98\%), 1,4-diaminobutane (DAB, 99\%) were purchased from SigmaAldrich. Ammonia solution $\left(\mathrm{NH}_{4} \mathrm{OH}, 30 \%\right)$ was purchased from Alfa Aesar. Sodium hydroxide $(\mathrm{NaOH}, 97 \%)$ and phosphoric acid $\left(\mathrm{H}_{3} \mathrm{PO}_{4}\right.$, 85\%) were obtained from Synth.

\subsection{Synthesis of magnetite nanoparticle $\left(\mathrm{Fe}_{3} \mathrm{O}_{4}\right)$}

Magnetite nanoparticles were prepared by the coprecipitation method. In a typical synthesis, $\mathrm{FeCl}_{3} \cdot 6 \mathrm{H}_{2} \mathrm{O}$ and $\mathrm{FeCl}_{2} \cdot 4 \mathrm{H}_{2} \mathrm{O}$ were dissolved in $570 \mathrm{~mL}$ of deionized water at a concentration of $0.050 \mathrm{~mol} \cdot \mathrm{L}^{-1}$ and $0.028 \mathrm{~mol} \cdot \mathrm{L}^{-1}$ respectively. Ferrous ions were in slight excess of magnetite stoichiometric molar ratio $\left(\mathrm{Fe}^{3+} / \mathrm{Fe}^{2+}=\right.$ $2: 1$ ) in order to account for the oxidation of ferrous. After purging with argon, $30 \mathrm{ml}$ of ammonia solution was added with vigorous mechanical stirring at $20,000 \mathrm{rpm}$, the resulted black suspension was stirred for $30 \mathrm{~min}$. The nanoparticles were magnetically separated from the supernatant and washed with water five times. The obtained magnetite nanoparticles were dispersed by sonication in deionized water.

\subsection{Preparation of amino-functionalized magnetite nanoparticles $\left(\mathrm{Fe}_{3} \mathrm{O}_{4}-\mathrm{NH}_{2}\right)$}

The surface modification of the nanoparticles was carried out through silanization process using APTS, in order to introduce amino groups at the nanoparticles surface [25]. In a three-necked round bottom flask equipped with a reflux condenser and inert atmosphere (Argon), $0.2 \mathrm{~g}$ of $\mathrm{Fe}_{3} \mathrm{O}_{4}$ nanoparticles were dispersed by sonication in $65 \mathrm{ml}$ of water-ethanol solution $(1: 1 \mathrm{v} / \mathrm{v})$. The $\mathrm{pH}$ of the suspension was adjusted to 9.0 with the addition of ammonia solution. Under magnetic stirring, $93.3 \mu \mathrm{L}$ of APTS was added to the suspension and allowed to react for $1 \mathrm{~h}$ at $40^{\circ} \mathrm{C}$. The nanoparticles were magnetically collected from suspension with an external magnetic field and washed four times with ethanol. The resulting nanoparticles sample was dispersed by sonication in deionized water.

\subsection{Synthesis of polysuccinimide (PSI)}

PSI was synthesized from the L-aspartic acid by acid-catalyzed thermal polycondensation [26].

A mixture of $3.0 \mathrm{~g}$ of $\mathrm{L}$-aspartic acid and $0.3 \mathrm{~g}$ of phosphoric acid were charged into a three-necked round-bottomed glass flask equipped with condenser and Dean-Stark trap for removing water, then heated at 200 ${ }^{\circ} \mathrm{C}$ in an oil bath under argon flow for $24 \mathrm{~h}$. The obtained powder was washed with deionized water and methanol several times and dried at $60{ }^{\circ} \mathrm{C}$ for $24 \mathrm{~h}$.

2.5. Preparation of magnetite coated with crosslinked polysuccinimide $\left(\mathrm{Fe}_{3} \mathrm{O}_{4}\right.$-PSI)

PSI was dissolved in DMF before adding $\mathrm{Fe}_{3} \mathrm{O}_{4}-\mathrm{NH}_{2}$ nanoparticles into the solution. The suspension was maintained at $70{ }^{\circ} \mathrm{C}$ for $24 \mathrm{~h}$ under magnetic stirring. After cooling to room temperature, it was added 1,4-diaminobutane (DAB) to the suspension and maintained for $3 \mathrm{~h}$ under magnetic stirring. The obtained nanoparticles were separated by an external magnetic field and washed with ethanol and water, prior to suspending in deionized water. Four samples were prepared from different concentration of the reactants according to Table 1.

\subsection{Preparation of magnetite coated with poly(aspartic acid) hydrogel} $\left(\mathrm{Fe}_{3} \mathrm{O}_{4}-\mathrm{PASP}\right)$

Samples $\mathrm{Fe}_{3} \mathrm{O}_{4}-\mathrm{PSI}_{1}, \mathrm{Fe}_{3} \mathrm{O}_{4}-\mathrm{PSI}_{2}$ and $\mathrm{Fe}_{3} \mathrm{O}_{4}-\mathrm{PSI}_{3}$ were suspended in $1 \mathrm{~mol} \cdot \mathrm{L}^{-1} \mathrm{NaOH}$ solution and magnetically stirred for $3 \mathrm{~h}$ at room temperature. Afterwards, suspensions were dialyzed against deionized water for $24 \mathrm{~h}$ to obtain samples $\mathrm{Fe}_{3} \mathrm{O}_{4}-\mathrm{PASP}_{1}, \mathrm{Fe}_{3} \mathrm{O}_{4}-\mathrm{PASP}_{2}$ and $\mathrm{Fe}_{3} \mathrm{O}_{4}-\mathrm{PASP}_{3}$, respectively.

\subsection{Samples characterization}

The crystalline structure of the samples was identified by X-ray powder diffraction (XRD) patterns recorded in the $2 \theta$ range $10-80^{\circ}$ on a Rigaku Geiger-Flex X-ray diffractometer using $\mathrm{Cu} \mathrm{K} \alpha$ radiation $(\lambda=1.5418 \AA)$.

The identification of the functional groups in the samples was performed by Diffuse Reflectance Infrared Fourier transform spectroscopy (DRIFTS). DRIFTS spectra were recorded on an FTIR spectrometer Vertex 70 (Bruker, Germany) using the Pike EasiDiff diffuse reflectance accessory. Dried samples were diluted in $\mathrm{KBr}$ and recorded with 128 scans in the range of $4000-400 \mathrm{~cm}^{-1}$ with a nominal resolution of $4.0 \mathrm{~cm}^{-1}$.

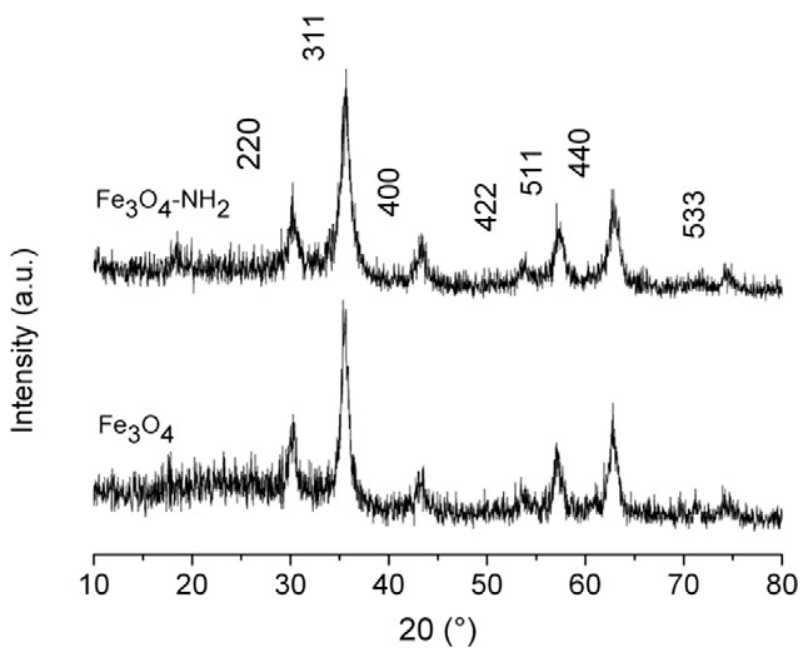

Fig. 1. XRD pattern of $\mathrm{Fe}_{3} \mathrm{O}_{4}$ and $\mathrm{Fe}_{3} \mathrm{O}_{4}-\mathrm{NH}_{2}$. 
Size and morphology of the nanoparticles were determined by Transmission Electron Microscopy (TEM). The TEM images of $\mathrm{Fe}_{3} \mathrm{O}_{4}$ were obtained in a Philips CM-120 microscope operating at $120 \mathrm{kV}$. The TEM images of $\mathrm{Fe}_{3} \mathrm{O}_{4}-\mathrm{NH}_{2}$ were obtained in a Philips $\mathrm{CM}-200 \mathrm{mi}-$ croscope operating at $200 \mathrm{kV}$. The HAADF-STEM images of $\mathrm{Fe}_{3} \mathrm{O}_{4}-\mathrm{PSI}_{3}$ and $\mathrm{Fe}_{3} \mathrm{O}_{4}$-PASP 3 were acquired using FEI Tecnai G2 F20 microscope operating at $200 \mathrm{kV}$.
Dilute isopropyl alcohol suspension of every specimen was dropped onto a carbon-coated copper grid and dried prior to analysis. It was measured the size of at least 100 nanoparticles using the software ImageJ, the average diameter and the standard deviation were calculated assuming a log-normal distribution.

The surface charge of the nanoparticles was determined by measurements of zeta potential using Zetasizer Nano ZS equipment

a)

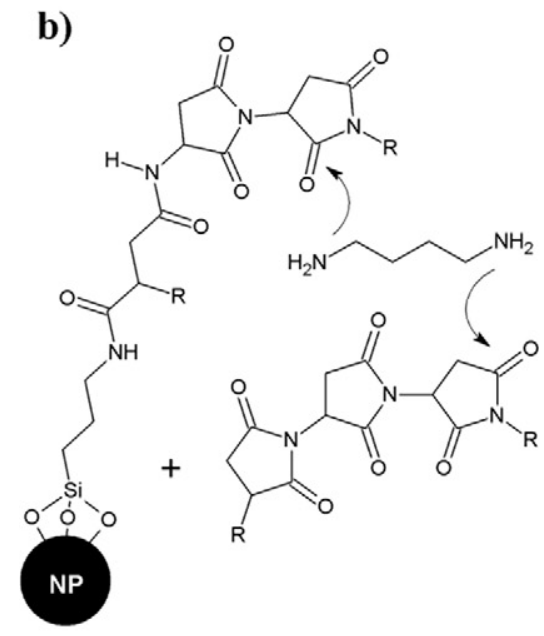

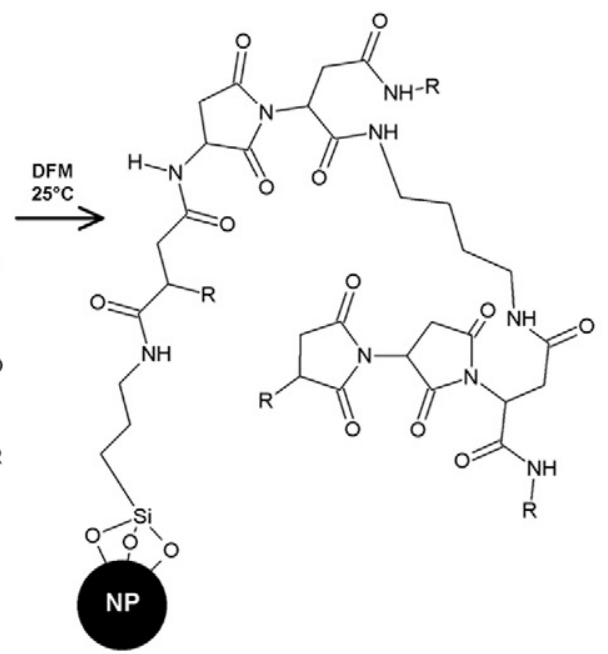

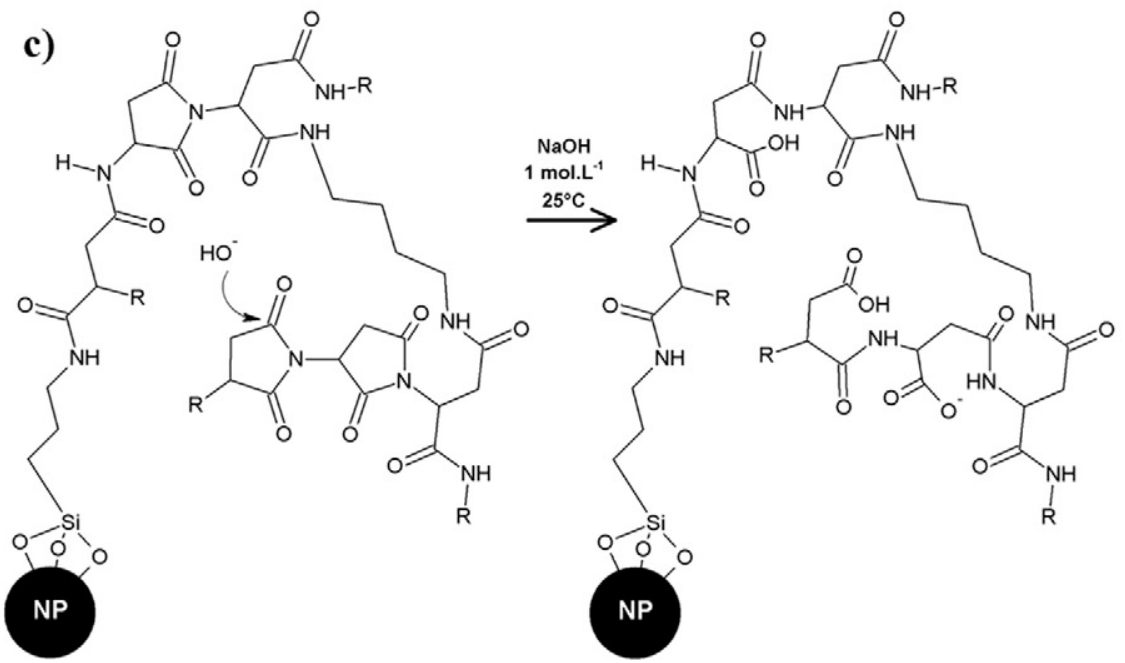

Fig. 2. Synthetic route of the multifunctional nanosystems. 


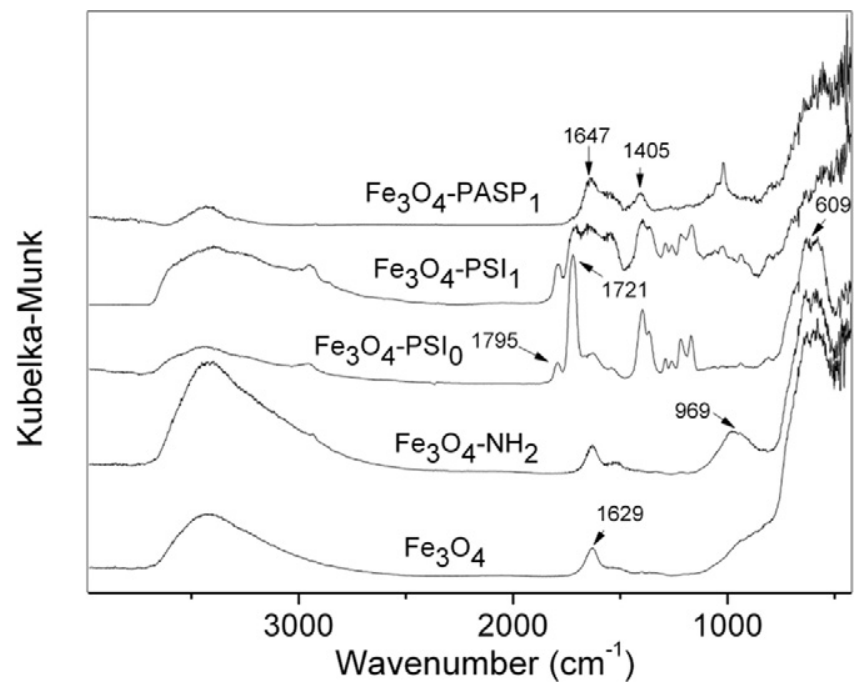

Fig. 3. DRIFTS spectra of samples $\mathrm{Fe}_{3} \mathrm{O}_{4}, \mathrm{Fe}_{3} \mathrm{O}_{4}-\mathrm{NH}_{2}, \mathrm{Fe}_{3} \mathrm{O}_{4}-\mathrm{PSI}_{0}, \mathrm{Fe}_{3} \mathrm{O}_{4}-\mathrm{PSI}_{1}$ and $\mathrm{Fe}_{3} \mathrm{O}_{4}$ $\mathrm{PASP}_{1}$.

(Malvern Instruments). The nanoparticles were dispersed at the concentration of $3.9 \times 10^{-2} \mathrm{mg} \cdot \mathrm{mL}^{-1}$ in $5 \times 10^{-3} \mathrm{~mol} \cdot \mathrm{L}^{-1} \mathrm{NaCl}$ solution. The zeta potential was measured in the $\mathrm{pH}$ range $2-11$. The $\mathrm{pH}$ was adjusted with MPT-2 Multi Purpose Titrator (Malvern Instruments) using $0.1 \mathrm{~mol} \cdot \mathrm{L}^{-1} \mathrm{NaOH}$ and $0.1 \mathrm{~mol} \cdot \mathrm{L}^{-1} \mathrm{HCl}$ solutions. All measurements were carried out in triplicate at $25^{\circ} \mathrm{C}$

The hydrodynamic diameter $\left(D_{h}\right)$ of the nanoparticles dispersed in water were determined by dynamic light scattering (DLS) in a Zetasizer Nano ZS (Malvern Instruments) with a fixed scattering angle of $173^{\circ}$ using a He-Ne laser $(\lambda=632.8 \mathrm{~nm})$ as the light source. The nanoparticles were dispersed by sonication in deionized water. The $\mathrm{pH}$ of the suspension was adjusted employing $0.25 \mathrm{~mol} \cdot \mathrm{L}^{-1} \mathrm{HCl}$ solution, all measurements were carried out at least in triplicate at $25^{\circ} \mathrm{C}$.

The cytotoxicity effect was evaluated on L929 cells (Instituto Adolfo Lutz, São Paulo, SP, Brazil) grown in Dulbeccco's Modified Eagle Medium (Gibco), supplemented with antibiotic-antimycotic solution (Sigma-Aldrich) and 10\% v/v fetal bovine serum (Gibco/inicrogen). The culture was maintained at $37{ }^{\circ} \mathrm{C}$ in an atmosphere of $5 \% \mathrm{CO}_{2}$ in 95\% air. (Thermo Scientific, USA). Cells were cultured until reaching confluence (90\%) and removed with trypsin $(0.05 \%)$ EDTA $(0.02 \%)$ (Gibco) in $1 \times$ PBS. The trypsin was inactivated by the addition of culture medium, and the cells were then subjected to centrifugation, resuspended and replated. The medium was changed two to three times per week. Total viable cell counts were made in a Neubauer chamber

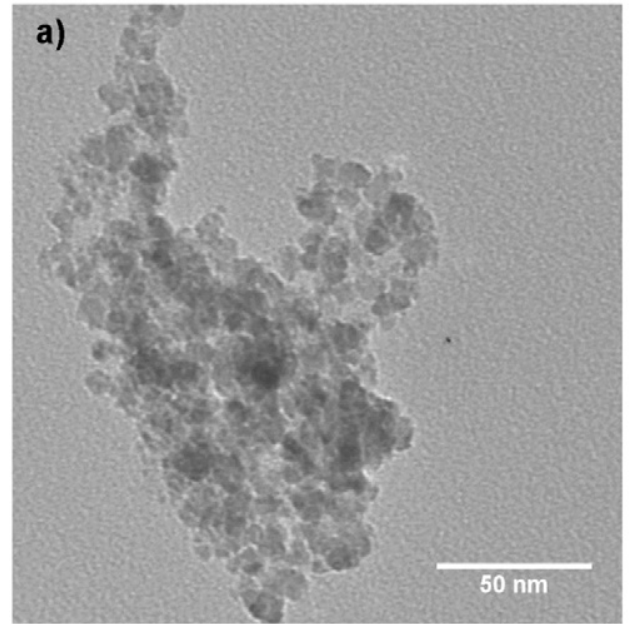

(New Optics), a suspension containing $1.0 \times 10^{4}$ cells $/ \mathrm{mL}$ was placed in 96 well plates (TPP) and incubated in a humidified atmosphere containing $5 \% \mathrm{CO}_{2}$ at $37^{\circ} \mathrm{C}$ for $24 \mathrm{~h}$.

After the incubation period, the culture medium was disposed. Then $200 \mu \mathrm{L}$ of fresh culture medium containing the following concentrations of $\mathrm{Fe}_{3} \mathrm{O}_{4}-\mathrm{PASP}_{1}$ was added to each orifice plate: $1000 ; 100 ; 10 ; 1 ; 0.1$; 0.01 ; and $0.001 \mu \mathrm{g} / \mathrm{mL}$. Negative control experiments were carried out using the growth culture media without the nanoparticles. In addition, $20 \mu \mathrm{L}$ of the Alamar Blue solution were added in each orifice plate to evaluate the cell metabolism by using the Alamar Blue ${ }^{\circledR}$ assay. The plates were maintained at $37{ }^{\circ} \mathrm{C}$ in an atmosphere of $5 \% \mathrm{CO}_{2}$ for $24 \mathrm{~h}$. Six wells were used for each experimental group.

The reading for the fluorescence of the samples was measured using the Fluoroskan Ascent FL fluorometer (Labsystems, Helsinki, Finland) at an excitation wavelength of $544 \mathrm{~nm}$ and an emission wavelength of $590 \mathrm{~nm}$. All experiments were performed three times $(n=18)$.

Cell viability in each case was expressed as the percentage of fluorescence compared to negative control. In addition, the morphology of cell attachment was observed and photographed by inverted light microscope (Leica Microsystems Wetzlar GmbH; Leica DMI3000B).

\section{Results and discussion}

XRD diffractograms of uncoated $\mathrm{Fe}_{3} \mathrm{O}_{4}$ and $\mathrm{Fe}_{3} \mathrm{O}_{4}-\mathrm{NH}_{2}$ are shown in Fig. 1, peaks are matched in position and in relative intensity to the characteristic pattern corresponding to inverse spinel structure of magnetite $\mathrm{Fe}_{3} \mathrm{O}_{4}$ (JCPDS - International Centre for Diffraction Data No. 33-0664), confirming the structured iron oxide in the samples and proved that the surface modification with APTS did not affect the magnetite structure of the iron oxide.

Whereas the carbonyl group of the imide ring is susceptible to nucleophilic attack, the reaction mechanism by which magnetic nanoparticles surface is coated by crosslinked PAA is proposed according to the following steps.

The amine groups on the $\mathrm{Fe}_{3} \mathrm{O}_{4}-\mathrm{NH}_{2}$ nanoparticles attack the carbonyl groups of PSI to form a covalent bond between the nanoparticle surface and PSI, thus the nanoparticle is coated by PSI $\left(\mathrm{Fe}_{3} \mathrm{O}_{4}-\mathrm{PSI}_{0}\right)$, this process is shown in Fig. 2a.

When DAB is added, each amine group performs a nucleophilic attack on a carbonyl group of PSI, then the PSI is crosslinked on the surface of the nanoparticles $\left(\mathrm{Fe}_{3} \mathrm{O}_{4}-\mathrm{PSI}_{1}\right)$, this process is shown in Fig. $2 \mathrm{~b}$.

Alkaline hydrolysis of the remaining imide rings on $\mathrm{Fe}_{3} \mathrm{O}_{4}-\mathrm{PSI}_{1}$ produces magnetic nanoparticles coated by crosslinked PAA $\left(\mathrm{Fe}_{3} \mathrm{O}_{4}-\mathrm{PASP}_{1}\right)$, this process is shown in Fig. 2c.

The surface modification of the nanoparticles in each step was examined by TEM, DRIFTS and zeta potential measurements. The

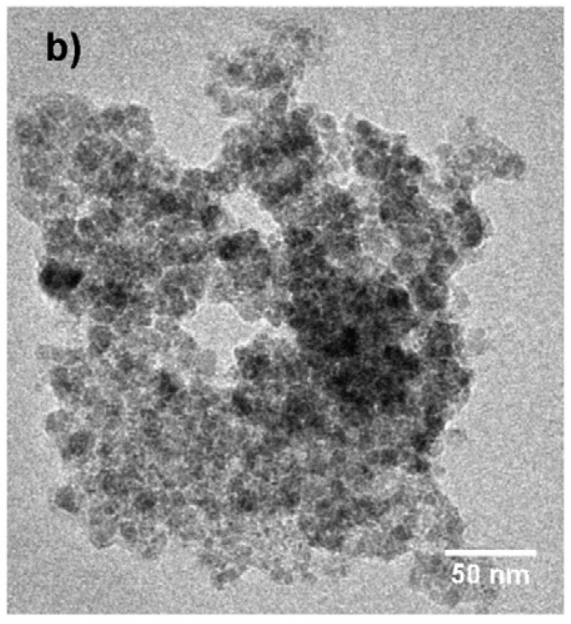


DRIFTS spectra of samples $\mathrm{Fe}_{3} \mathrm{O}_{4}, \mathrm{Fe}_{3} \mathrm{O}_{4}-\mathrm{NH}_{2}, \mathrm{Fe}_{3} \mathrm{O}_{4}-\mathrm{PSI}_{0}, \mathrm{Fe}_{3} \mathrm{O}_{4}-\mathrm{PSI}_{1}$ and $\mathrm{Fe}_{3} \mathrm{O}_{4}-\mathrm{PASP}_{1}$ are depicted in Fig. 3.

$\mathrm{Fe}_{3} \mathrm{O}_{4}$ and $\mathrm{Fe}_{3} \mathrm{O}_{4}-\mathrm{NH}_{2}$ exhibit three characteristics bands related to iron oxide: a band centered at about $609 \mathrm{~cm}^{-1}$ assigned to the $\mathrm{Fe}-\mathrm{O}$ stretching vibration and the bands centered at $3420 \mathrm{~cm}^{-1}$ and $1629 \mathrm{~cm}^{-1}$ are assigned to stretching and bending vibrations of hydroxyl on the nanoparticles surface [27]. The sample $\mathrm{Fe}_{3} \mathrm{O}_{4}-\mathrm{NH}_{2}$ presents an additional band at about $969 \mathrm{~cm}^{-1}$ related to $\mathrm{Si}-\mathrm{O}$ stretching vibration, confirming the silanization of the magnetite nanoparticles surface [28].

The bands at 1721 and $1795 \mathrm{~cm}^{-1}$ in $\mathrm{Fe}_{3} \mathrm{O}_{4}-\mathrm{PSI}_{0}$ are characteristics of the PSI repeat unit and are related to the antisymmetric and symmetric stretching modes of five-membered imide ring, respectively, demonstrating that PSI polymeric chains were anchored to the surface of the nanoparticles [29-30].

When the DAB crosslinked the PSI polymeric chains, some of the imide rings are opened and consequently the quantity of the rings decreased and amide groups are produced [30]. In sample $\mathrm{Fe}_{3} \mathrm{O}_{4}-\mathrm{PSI}_{1}$, the intensity of the band at $1721 \mathrm{~cm}^{-1}$ is lower than in sample $\mathrm{Fe}_{3} \mathrm{O}_{4}-\mathrm{PSI}_{0}$ due to the decrease of the imide rings. The presence of amide was verified by the bands centered at 1647 and $1546 \mathrm{~cm}^{-1}$, which are assigned to the amide I and amide II vibration modes, respectively [31], these results prove the presence of crosslinked PSI in $\mathrm{Fe}_{3} \mathrm{O}_{4}-\mathrm{PSI}_{1}$.

The characteristics bands of imide rings are missing in the DRIFTS spectrum of $\mathrm{Fe}_{3} \mathrm{O}_{4}-\mathrm{PASP}_{1}$, however, it presents a broad band at $1600 \mathrm{~cm}^{-1}$ due to the superposition of carboxyl, amide I, amide II and carboxylate asymmetric stretching vibration mode. Also presents a band at $1405 \mathrm{~cm}^{-1}$ related to the carboxylate symmetric stretching vibration mode [32]. These results indicate that the remained imide rings of the PSI were totally opened by the hydrolysis process to form amide and carboxyl groups, therefore, the sample $\mathrm{Fe}_{3} \mathrm{O}_{4}$-PASP 1 presents crosslinked poly(aspartic acid).

Fig. 4 presents the TEM images of the samples $\mathrm{Fe}_{3} \mathrm{O}_{4}$ and $\mathrm{Fe}_{3} \mathrm{O}_{4}-\mathrm{NH}_{2}$, in which nanoparticles are nearly spherical in shape and present some degree of agglomeration. After the silanization, the average particle size increased from $6.0 \pm 1.2 \mathrm{~nm}$ to $7.1 \pm 1.6 \mathrm{~nm}$ evidencing the existence of a silica layer over the magnetite nanoparticles in the samples $\mathrm{Fe}_{3} \mathrm{O}_{4}-\mathrm{NH}_{2}$.

The signal in HAADF-STEM is proportional to the atomic number, appearing brighter the areas with a higher atomic number $(Z)$.

HAADF-STEM images of $\mathrm{Fe}_{3} \mathrm{O}_{4}-\mathrm{PSI}_{3}$ and $\mathrm{Fe}_{3} \mathrm{O}_{4}$-PASP 3 are presented in Fig. 5, these show the nanosystems formed by agglomerated magnetite nanoparticles (brighter region with higher Z) surrounded by polymeric phase (gray region). The polymeric phase is more extended in $\mathrm{Fe}_{3} \mathrm{O}_{4}-\mathrm{PASP}_{3}$ than in $\mathrm{Fe}_{3} \mathrm{O}_{4}-\mathrm{PSI}_{3}$. This is due, as will be seen later, to the higher presence of carboxylate anions in the PASP hydrogel than in PSI gel.

The zeta potential as a function of $\mathrm{pH}$ can be observed in Fig. 6, from which the isoelectric point (IEP) was determined as the value of $\mathrm{pH}$ where the zeta potential equals zero [33].

In aqueous suspension, the surface of the nanoparticles generates electric charges due to the adsorption of ions and the ionization of the functional groups on the nanoparticles surface [33]. If the functional groups have acid-base characteristics, the degree of ionization depends on the suspension $\mathrm{pH}$. The value of the zeta potential also allows evaluating the colloidal stability. Nanoparticles with zeta potential higher than $+30 \mathrm{mV}$ or lesser than $-30 \mathrm{mV}$ have colloidal stability due to the electrostatic repulsion, avoiding the agglomeration of the nanoparticles [34].

The IEP of $\mathrm{Fe}_{3} \mathrm{O}_{4}$ is 6.1 (Fig. 6), which was the expected value considering the presence of amphoteric hydroxyl groups on the surface of the magnetite nanoparticles.

In $\mathrm{Fe}_{3} \mathrm{O}_{4}-\mathrm{NH}_{2}$, the presence of the amine groups (with the capacity of being protonated and generates positive charges) on the nanoparticles surface is reflected in the increase of the IEP to 8.5, this value agrees with previous data [35-36].
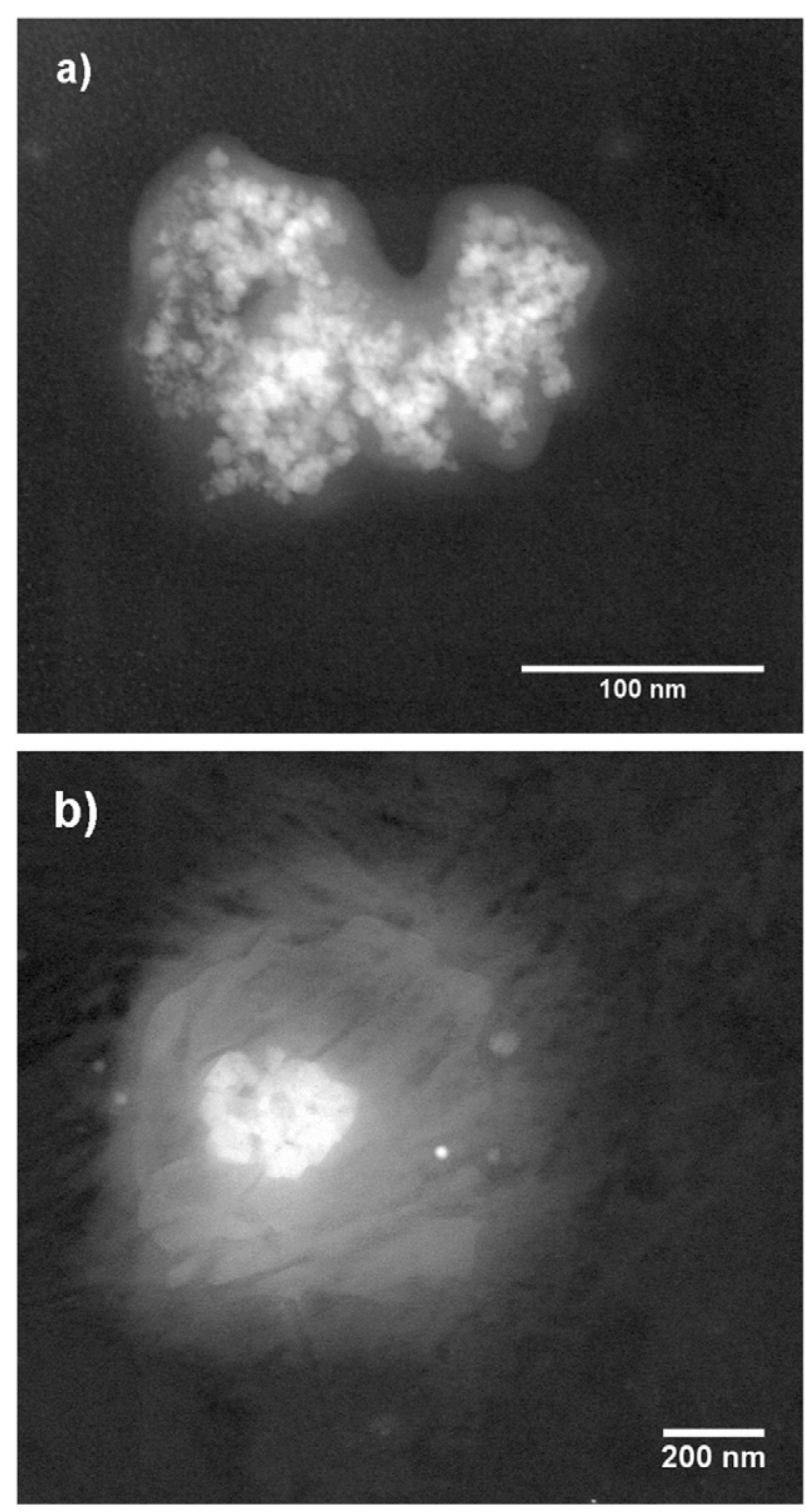

Fig. 5. HAADF-STEM images: a) $\mathrm{Fe}_{3} \mathrm{O}_{4}-\mathrm{PSI}_{3}$, b) $\mathrm{Fe}_{3} \mathrm{O}_{4}-\mathrm{PASP}_{3}$.

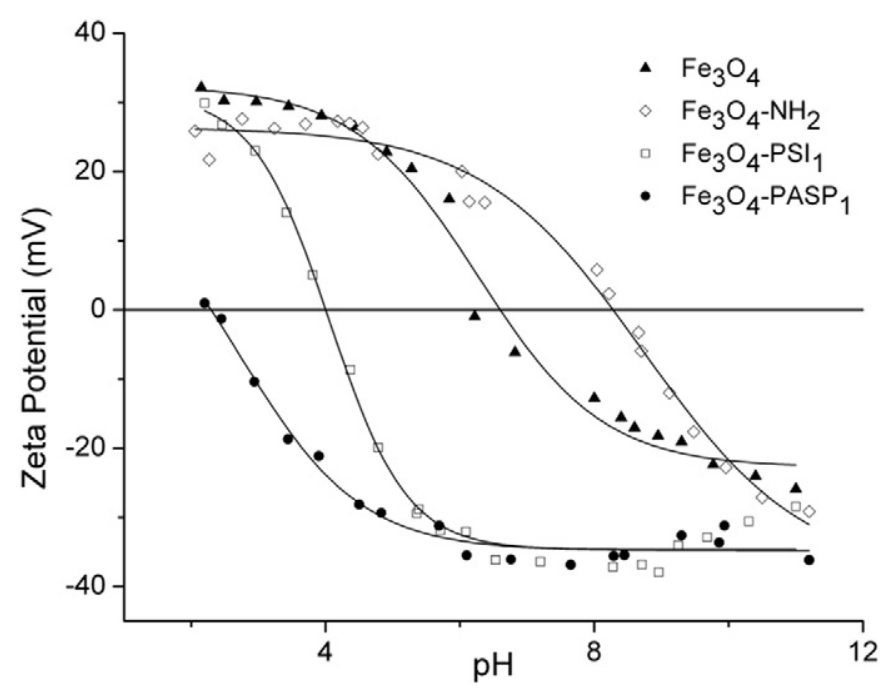

Fig. 6. Influence of the $\mathrm{pH}$ on the zeta potential of $\mathrm{Fe}_{3} \mathrm{O}_{4}(\boldsymbol{\Delta}), \mathrm{Fe}_{3} \mathrm{O}_{4}-\mathrm{NH}_{2}(\diamond), \mathrm{Fe}_{3} \mathrm{O}_{4}-\mathrm{PSI}_{1}$ $(\square)$ and $\mathrm{Fe}_{3} \mathrm{O}_{4}-\mathrm{PASP}_{1}($ 

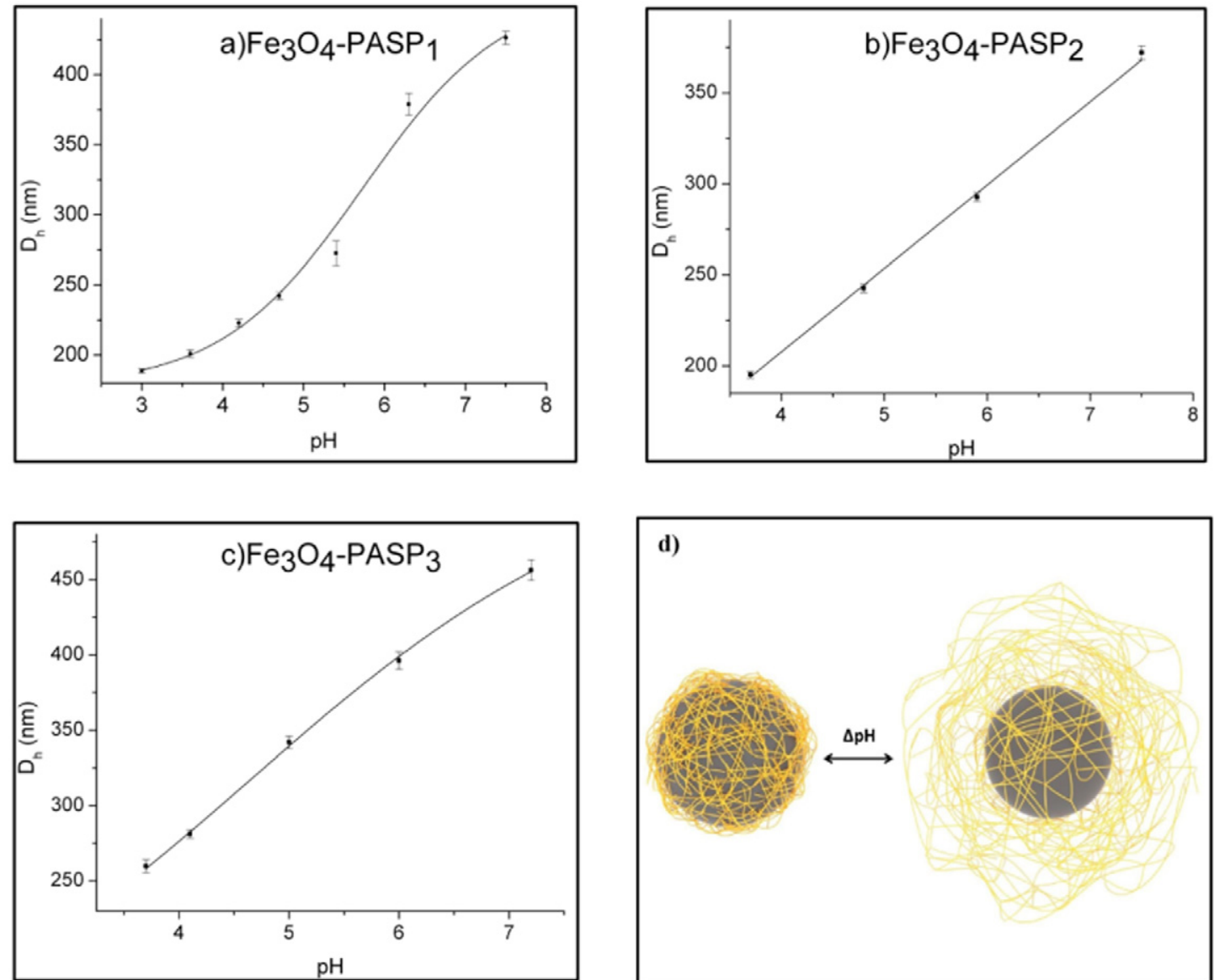

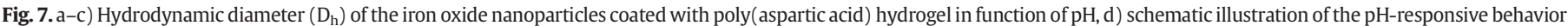
of the nanosystems.

$\mathrm{Fe}_{3} \mathrm{O}_{4}-\mathrm{PSI}_{1}$ displays an IEP of 4.0 , indicating the presence of functional groups able to generate negative charges. In aqueous suspension, some of the imide rings in the PSI are opened by the hydrolysis process even at $\mathrm{pH}=7$, producing carboxyl groups that provide a negative charge to the system [37].

When the remained imide rings were opened through the basic hydrolysis, more carboxyl groups were formed; this was confirmed by the IEP of $\mathrm{Fe}_{3} \mathrm{O}_{4}$-PASP 1 which has a value of 2.3.

Applications in biomedicine require magnetic nanoparticles with colloidal stability in the environment $\mathrm{pH}$. The $\mathrm{pH}$ in normal tissues and blood is about 7.4, however, some environments are more acidic, such as cancer tissues ( $\mathrm{pH}$ 6.5-7.2), endosomes ( $\mathrm{pH}$ 5.0-6.5) and lysosomes ( $\mathrm{pH} 4.5-5.0)[2,15]$.

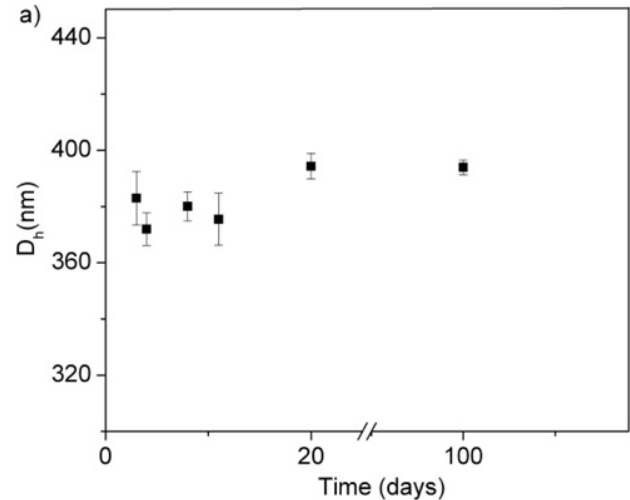

The zeta potential of $\mathrm{Fe}_{3} \mathrm{O}_{4}-\mathrm{PASP}_{1}$ is less than $-30 \mathrm{mV}$ when the $\mathrm{pH}$ of the suspension is higher than 4.5 , therefore the magnetite nanoparticles surface modified by poly(aspartic acid) hydrogel have colloidal stability in the biomedical applications $\mathrm{pH}$ range due to the negative charges in the poly(aspartic acid) hydrogel, which also acts as physical barrier providing steric stabilization.

The effect of the $\mathrm{pH}$ in the $\mathrm{D}_{\mathrm{h}}$ of magnetite nanoparticles surface modified by poly(aspartic acid) hydrogel $\left(\mathrm{Fe}_{3} \mathrm{O}_{4}\right.$-PASP) in aqueous media is shown in Fig. 7 , in which the $\mathrm{D}_{\mathrm{h}}$ decrease with decreasing the $\mathrm{pH}$ value, indicating that the nanosystems display $\mathrm{pH}$-responsive characteristics. At neutral environment, the presence of negatively charged carboxylate groups is considerable in PASP chains, producing electrostatic repulsion between the polymeric chains. The hydrogel store

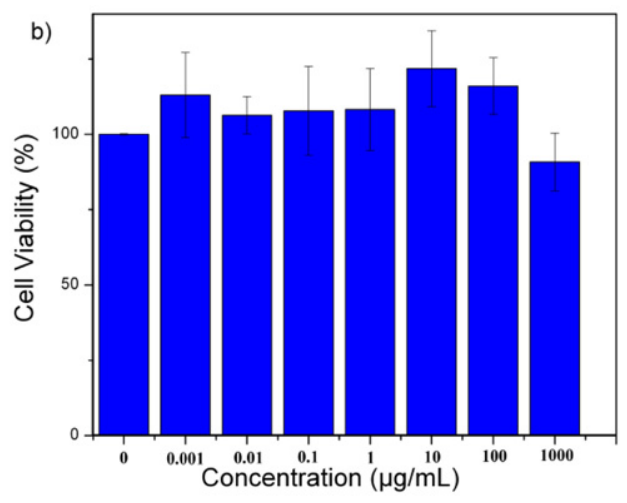

Fig. 8. a) Hydrodynamic diameter $\left(\mathrm{D}_{\mathrm{h}}\right)$ of $\mathrm{Fe}_{3} \mathrm{O}_{4}$ - $\mathrm{PASP}_{1}$ in function of the days at $25{ }^{\circ} \mathrm{C}$ and $\mathrm{pH}$ 7, b) cell viability for $\mathrm{Fe}_{3} \mathrm{O}_{4}$ - $\mathrm{PASP}_{1}$ at various concentrations. 

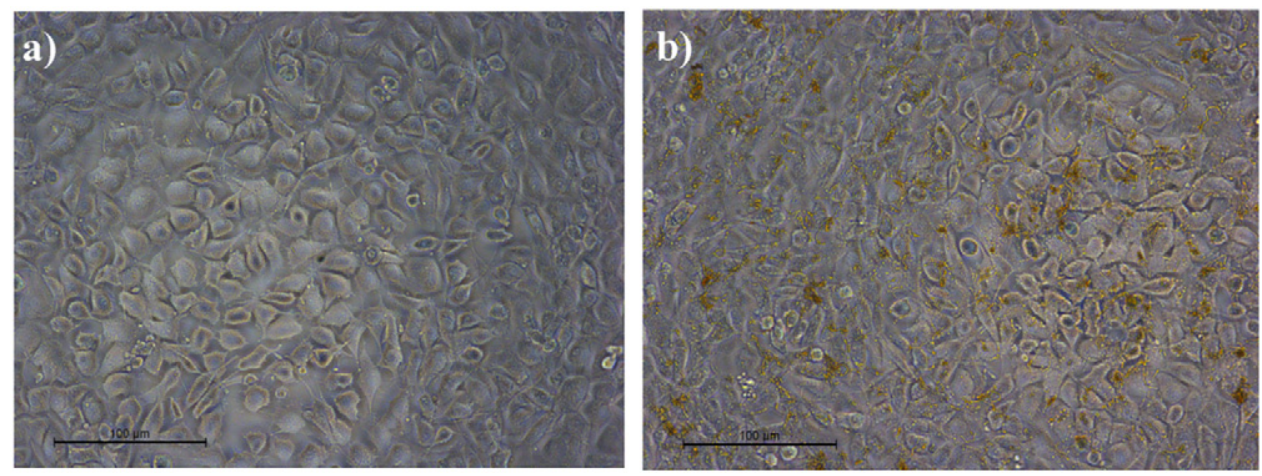

Fig. 9. Photomicrographs of $\mathrm{L} 929$ cells in presence of $\mathrm{Fe}_{3} \mathrm{O}_{4}-\mathrm{PASP}_{1}$ at concentrations: a) $0 \mu \mathrm{g} / \mathrm{mL}-\mathrm{Control,} \mathrm{b)} 10 \mu \mathrm{g} / \mathrm{mL}$.

water molecules for stabilizing the electrical charges and separate the polymeric chains. As the $\mathrm{pH}$ of the suspension decreases, the amount of carboxylate anions in the hydrogel decreases owing to the protonation of these groups, which reduces the electrostatic repulsion. Consequently, the hydrogel shrinks and the volume of the nanosystem is reduced. Then, the volume of the $\mathrm{Fe}_{3} \mathrm{O}_{4}$-PASP nanosystems is a function of the ionization degree of the PASP hydrogel $[6,8]$. Below of approximately pH 3.0 the nanosystems misplaced the colloidal stability and agglomeration took place.

The capacity to change the volume of the hydrogel in response to $\mathrm{pH}$ variation is influenced by the degree of crosslinking of the hydrogel, which is proportional to the number of linkages between the polymeric chains in the hydrogel. A high degree of crosslinking improves the rigidity of the hydrogel, restricting the movement of polymeric chains and also limiting the variation of the hydrogel volume [38-40].

The $\mathrm{Fe}_{3} \mathrm{O}_{4}$-PASP 1 and $\mathrm{Fe}_{3} \mathrm{O}_{4}$ - $\mathrm{PASP}_{2}$ samples showed a reduction in $D_{h}$ until reaching a value of approximately $180 \mathrm{~nm}$, whereas the $D_{h}$ of $\mathrm{Fe}_{3} \mathrm{O}_{4}-\mathrm{PASP}_{3}$ reached a value of about $260 \mathrm{~nm}$. During the synthesis process, for a given PSI quantity, an increase in the crosslinker agent, rise the degree of crosslinking of hydrogel [39].

The $\mathrm{Fe}_{3} \mathrm{O}_{4}-\mathrm{PASP}_{3}$ sample was prepared with a concentration of 1,4diaminobutane (crosslinker molecule) larger than the other samples (Table 1), then the degree of crosslinking was higher in $\mathrm{Fe}_{3} \mathrm{O}_{4}-\mathrm{PASP}_{3}$, limiting the shrinkage of the hydrogel.

Fig. 8a shown the $\mathrm{D}_{\mathrm{h}}$ of $\mathrm{Fe}_{3} \mathrm{O}_{4}-\mathrm{PASP}_{1}$ in function of the days, it can be seen no significant change in the $\mathrm{D}_{\mathrm{h}}$ after 100 days of storage. The agglomeration process is avoided; therefore the nanosystems have high colloidal stability.

Fig. 8b displays the cell viability evaluated by the Alamar Blue test. The results, in accordance with ISO standard 10993-5, show that the nanoparticles at the tested concentrations are not cytotoxic with cellular viability $\geq 90 \%$, when compared with the negative control group. The morphology of L929 fibroblasts cultured on the control group and with nanoparticles at the tested concentrations was observed by inverted light microscopy, as shown in Figs. 9 and S1 (Supplementary material). It can be seen that the cells cultivated with nanoparticles had preserved morphology without signs of cell death at the all tested concentrations.

It is worth to mention that the method of coating with poly(aspartic acid) hydrogel could be extended to another types of nanoparticles, such as gold or quantum dots if the surface of these nanoparticles is functionalized by amine groups.

\section{Conclusions}

Novel biocompatible and multifunctional nanosystems $\mathrm{Fe}_{3} \mathrm{O}_{4}$-PASP hydrogel have been successfully prepared as nanocomposites responsive to magnetic field and $\mathrm{pH}$. The presence of ionizable carboxyl groups in the PASP hydrogel confers its $\mathrm{pH}$ responsive behavior. The hydrodynamic diameter of the nanosystems decreased as $\mathrm{pH}$ decreased. The hydrogel provides colloidal stability through electrostatic and steric stabilization. The nanosystems exhibited no cytotoxicity, indicating that the developed multifunctional nanosystems could be used in a wide range of biomedical applications, such as magnetic drug delivery systems, in which the changes in the $\mathrm{pH}$ could release the loaded drug.

Supplementary data to this article can be found online at http://dx. doi.org/10.1016/j.msec.2017.03.244.

\section{Acknowledgements}

The authors would like to thank Conselho Nacional de Desenvolvimento Científico e Tecnológico (CNPq) and Fundação de Amparo à Pesquisa do Estado de São Paulo (FAPESP) for the financial support and Dr. Daniel F. Segura for designing Fig. 7d.

\section{References}

[1] S.F. Medeiros, A.M. Santos, H. Fessi, A. Elaissari, Stimuli-responsive magnetic particles for biomedical applications, Int. J. Pharm. 403 (2011) 139-161, http://dx.doi. org/10.1016/j.ijpharm.2010.10.011.

[2] R. Cheng, F. Meng, C. Deng, H.-A. Klok, Z. Zhong, Dual and multi-stimuli responsive polymeric nanoparticles for programmed site-specific drug delivery, Biomaterials 34 (2013) 3647-3657, http://dx.doi.org/10.1016/j.biomaterials.2013.01.084.

[3] E. Cabane, X. Zhang, K. Langowska, C.G. Palivan, W. Meier, Stimuli-responsive polymers and their applications in nanomedicine, Biointerphases 7 (2012) 1-27, http://dx.doi.org/10.1007/s13758-011-0009-3.

[4] A. Chan, R.P. Orme, R.A. Fricker, P. Roach, Remote and local control of stimuli responsive materials for therapeutic applications, Adv. Drug Deliv. Rev. 65 (2013) 497-514, http://dx.doi.org/10.1016/j.addr.2012.07.007.

[5] A.P. Chiriac, L.E. Nita, I. Neamtu, Poly(ethylene glycol) functionalized by polycondensing procedure with poly(succinimide), Polymer 55 (2010) 641-645.

[6] T. Gyenes, V. Torma, B. Gyarmati, M. Zrínyi, Synthesis and swelling properties of novel pH-sensitive poly(aspartic acid) gels, Acta Biomater. 4 (2008) 733-744, http://dx.doi.org/10.1016/j.actbio.2007.12.004.

[7] T. Gyenes, V. Torma, M. Zrínyi, Swelling properties of aspartic acid-based hydrogels, Colloids Surf. A Physicochem. Eng. Asp. 319 (2008) 154-158, http://dx.doi.org/10. 1016/j.colsurfa.2007.06.016.

[8] Y. Zhao, H. Su, L. Fang, T. Tan, Superabsorbent hydrogels from poly(aspartic acid) with salt-, temperature- and pH-responsiveness properties, Polymer 46 (2005) 5368-5376, http://dx.doi.org/10.1016/j.polymer.2005.04.015.

[9] M. Zrinyi, T. Gyenes, D. Juriga, J.-H. Kim, Volume change of double cross-linked poly(aspartic acid) hydrogels induced by cleavage of one of the crosslinks, Acta Biomater. 9 (2013) 5122-5131, http://dx.doi.org/10.1016/j.actbio.2012.08.046.

[10] L. Zhu, D. Wang, X. Wei, X. Zhu, J. Li, C. Tu, et al., Multifunctional pH-sensitive superparamagnetic iron-oxide nanocomposites for targeted drug delivery and MR imaging, J. Control. Release 169 (2013) 228-238, http://dx.doi.org/10.1016/j. jconrel.2013.02.015.

[11] S. Yu, G. Wu, X. Gu, J. Wang, Y. Wang, H. Gao, et al., Magnetic and pH-sensitive nanoparticles for antitumor drug delivery, Colloids Surf. B. Biointerfaces 103 (2013) 15-22, http://dx.doi.org/10.1016/j.colsurfb.2012.10.041.

[12] S. Bhattacharya, F. Eckert, V. Boyko, A. Pich, Temperature-, pH-, and magnetic-fieldsensitive hybrid microgels, Small 3 (2007) 650-657, http://dx.doi.org/10.1002/smll. 200600590.

[13] A.K. Gupta, M. Gupta, Synthesis and surface engineering of iron oxide nanoparticles for biomedical applications, Biomaterials 26 (2005) 3995-4021, http://dx.doi.org/ 10.1016/j.biomaterials.2004.10.012.

[14] D. Ling, T. Hyeon, Chemical design of biocompatible iron oxide nanoparticles for medical applications, Small 9 (2013) 1450-1466, http://dx.doi.org/10.1002/smll. 201202111.

[15] M. Mahmoudi, S. Sant, B. Wang, S. Laurent, T. Sen, Superparamagnetic iron oxide nanoparticles (SPIONs): development, surface modification and applications in 
chemotherapy, Adv. Drug Deliv. Rev. 63 (2011) 24-46, http://dx.doi.org/10.1016/j. addr.2010.05.006.

[16] C. Xu, S. Sun, New forms of superparamagnetic nanoparticles for biomedical applications, Adv. Drug Deliv. Rev. 65 (2013) 732-743, http://dx.doi.org/10.1016/j.addr. 2012.10.008.

[17] J.K. Oh, J.M. Park, Iron oxide-based superparamagnetic polymeric nanomaterials: design, preparation, and biomedical application, Prog. Polym. Sci. 36 (2011) 168-189, http://dx.doi.org/10.1016/j.progpolymsci.2010.08.005.

[18] K. Aurich, M. Schwalbe, J.H. Clement, W. Weitschies, N. Buske, Polyaspartate coated magnetite nanoparticles for biomedical applications, J. Magn. Magn. Mater. 311 (2007) 1-5, http://dx.doi.org/10.1016/j.jmmm.2006.11.154.

[19] P. Yang, W. Chen, C. Wang, Preparation and in vitro cytotoxicity study of poly (aspartic acid) stabilized magnetic nanoparticles, Front. Chem. Chin. 6 (2011) 9-14, http://dx.doi.org/10.1007/s11458-011-0222-0.

[20] S. Wan, J. Huang, M. Guo, H. Zhang, Y. Cao, H. Yan, Biocompatible superparamagnetic iron oxide nanoparticle dispersions stabilized with poly(ethylene glycol) oligo(aspartic acid) hybrids, J. Biomed. Mater. Res. Part A 80A (2006) 946-954, http://dx.doi.org/10.1002/jbm.a.31022.

[21] A.P. Chiriac, I. Neamtu, L.E. Nita, M.T. Nistor, A study on the composites based on poly(succinimide)-b-poly(ethylene glycol) and ferrite and their magnetic response Compos. Part B Eng. 42 (2011) 1525-1531, http://dx.doi.org/10.1016/j.compositesb. 2011.04.018.

[22] H. Kim, D. Kim, Polysuccinimide graft copolymer nano aggregates encapsulating magnetites for imaging probe, Macromol. Res. 20 (2012) 259-265, http://dx.doi. org/10.1007/s13233-012-0052-z.

[23] M. Kumagai, Y. Imai, T. Nakamura, Y. Yamasaki, M. Sekino, S. Ueno, et al., Iron hydroxide nanoparticles coated with poly(ethylene glycol)-poly(aspartic acid) block copolymer as novel magnetic resonance contrast agents for in vivo cancer imaging, Colloids Surf. B. Biointerfaces 56 (2007) 174-181, http://dx.doi.org/10.1016/j. colsurfb.2006.12.019

[24] H.-M. Yang, B.C. Oh, J.H. Kim, T. Ahn, H.-S. Nam, C.W. Park, et al., Multifunctional poly(aspartic acid) nanoparticles containing iron oxide nanocrystals and doxorubicin for simultaneous cancer diagnosis and therapy, Colloids Surf. A Physicochem. Eng. Asp. 391 (2011) 208-215, http://dx.doi.org/10.1016/j.colsurfa.2011.04.032.

[25] X.-C. Shen, X.-Z. Fang, Y.-H. Zhou, H. Liang, Synthesis and characterization of 3aminopropyltriethoxysilane-modified superparamagnetic magnetite nanoparticles, Chem. Lett. 33 (2004) 1468-1469, http://dx.doi.org/10.1246/cl.2004.1468.

[26] J.-C. Yeh, H.-H. Yang, Y.-T. Hsu, C.-M. Su, T.-H. Lee, S.-L. Lou, Synthesis and characteristics of biodegradable and temperature responsive polymeric micelles based on poly(aspartic acid)-g-poly(N-isopropylacrylamide-co-N,N-dimethylacrylamide) Colloids Surf. A Physicochem. Eng. Asp. 421 (2013) 1-8, http://dx.doi.org/10.1016/ j.colsurfa.2012.12.014.
[27] X.-Y. Sun, S.-S. Yu, J.-Q. Wan, K.-Z. Chen, Facile graft of poly(2-methacryloyloxyethyl phosphorylcholine) onto $\mathrm{Fe}_{3} \mathrm{O}_{4}$ nanoparticles by ATRP: synthesis, properties, and biocompatibility, J. Biomed. Mater. Res. A 101 (2013) 607-612, http://dx.doi.org/ 10.1002/jbm.a.34343.

[28] R.A. Bini, R.F.C. Marques, F.J. Santos, J.A. Chaker, M. Jafelicci, Synthesis and functionalization of magnetite nanoparticles with different amino-functional alkoxysilanes, J. Magn. Magn. Mater. 324 (2012) 534-539, http://dx.doi.org/10. 1016/j.jmmm.2011.08.035.

[29] A.M. Pistorius, P.J. Groenen, W.J. De Grip, Infrared analysis of peptide succinimide derivatives, Int. J. Pept. Protein Res. 42 (1993) 570-577.

[30] L. Fang, J. Yang, T.W. Tan, Effect of drying process on structure and property of polyaspartic acid resin, J. Sol-Gel Sci. Technol. 40 (2006) 89-99, http://dx.doi.org/10. 1007/s10971-006-9084-1.

[31] A. Barth, C. Zscherp, What vibrations tell about proteins, Q. Rev. Biophys. 35 (2002) 369-430, http://dx.doi.org/10.1017/S0033583502003815.

[32] R.M. Silverstein, F.X. Webster, D.J. Kiemle, Spectrometric Identification of Organic Compounds, seventh ed. John Wiley \& Sons, New York, 2005.

[33] K. Suttiponparnit, J. Jiang, M. Sahu, S. Suvachittanont, T. Charinpanitkul, P. Biswas, Role of surface area, primary particle size, and crystal phase on titanium dioxide nanoparticle dispersion properties, Nanoscale Res. Lett. 6 (2010) 27, http://dx.doi. org/10.1007/s11671-010-9772-1.

[34] E.J. Cho, H. Holback, K.C. Liu, S.A. Abouelmagd, J. Park, Y. Yeo, Nanoparticle characterization: state of the art, challenges, and emerging technologies, Mol. Pharm. 10 (2013) 2093-2110, http://dx.doi.org/10.1021/mp300697h.

[35] S. Čampelj, D. Makovec, M. Drofenik, Functionalization of magnetic nanoparticles with 3-aminopropyl silane, J. Magn. Magn. Mater. 321 (2009) 1346-1350, http:// dx.doi.org/10.1016/j.jmmm.2009.02.036.

[36] Z. Xu, Q. Liu, J.A. Finch, Silanation and stability of 3-aminopropyl triethoxy silane on nanosized superparamagnetic particles: I. Direct silanation, Appl. Surf. Sci. 120 (1997) 269-278, http://dx.doi.org/10.1016/S0169-4332(97)00234-1.

[37] P.D. Hoagland, S.W. Fox, The hydrolysis of polyimides, Experientia 29 (1973) 962-964.

[38] V. Torma, T. Gyenes, Z. Szakács, M. Zrínyi, A novel potentiometric method for the determination of real crosslinking ratio of poly(aspartic acid) gels, Acta Biomater. 6 (2010) 1186-1190, http://dx.doi.org/10.1016/j.actbio.2009.08.045.

[39] J.R. Moon, B.S. Kim, J. Kim, Preparation and properties of novel biodegradable hydrogel based on cationic polyaspartamide derivative, Bull. Kor. Chem. Soc. 27 (2006) 981-985.

[40] E. Saldivar-Guerra, E. Vivaldo-Lima, Handbook of Polymer Synthesis, Characterization, and Processing, first ed. John Wiley \& Sons, New Jersey, 2013. 